\title{
Delay from Symptom Onset Increases the Conversion Rate in Laparoscopic Cholecystectomy for Acute Cholecystitis
}

\author{
Sirwan M. Hadad · Jayant S. Vaidya - Lee Baker · \\ Hoey C. Koh · Timothy P. Heron · Kashif Hussain · \\ Alastair M. Thompson
}

Published online: 4 October 2008

(c) Société Internationale de Chirurgie 2008

\section{Erratum to: World J Surg}

\section{DOI 10.1007/s00268-007-9050-2}

In the above-mentioned article, published in the issue of the World Journal of Surgery, volume 31 issue 6, the following author's name was inadvertently omitted: Mr. Kashif Hussain.
The correct list of authors should read:

S. M. Hadad, J. S. Vaidya, L. Baker, H. C. Koh, T. P. Heron, K. Hussain, A. M. Thompson

Department of Surgery and Molecular Oncology, Ninewells Hospital and Medical School, Dundee, UK.

The online version of the original article can be found under doi:10.1007/s00268-007-9050-2.

S. M. Hadad $(\bowtie)$. J. S. Vaidya · L. Baker .

H. C. Koh - T. P. Heron - K. Hussain - A. M. Thompson

Department of Surgery and Molecular Oncology, Ninewells

Hospital and Medical School, Dundee DD1 9SY, UK

e-mail: s.hadad@hotmail.co.uk 